\title{
Proposta de atuação da fisioterapia na saúde da criança e do adolescente: uma necessidade na atenção básica
}

Proposal for a performance of physical therapy on the health of children and adolescents: a need in primary care

Maria Laura Oliveira David', Maria Ângela Gonçalves de Oliveira Ribeiro², Maria de Lurdes Zanolli³, Roberto Teixeira Mendes ${ }^{4}$, Maíra Seabra de Assumpção ${ }^{5}$, Camila Isabel Santos Schivinski ${ }^{6}$

' Pós-graduada em Fisioterapia Pediátrica pelo Departamento de Pediatria da Universidade Estadual de Campinas (UNICAMP) - Campinas (SP), Brasil. laladavid@hotmail.com

2 Doutora em Saúde da Criança e do Adolescente pela Faculdade de Ciências Médicas pela Universidade Estadual de Campinas (UNICAMP) - Campinas (SP), Brasil. Coordenadora dos cursos de Pós-graduação em Fisioterapia Pediátrica da Universidade Estadual de Campinas (UNICAMP) -

Campinas (SP), Brasil.

ribeiromago@gmail.com

3 Doutora em Pediatria / Saúde da Criança e do Adolescente pela Universidade Estadual de Campinas (UNICAMP) - Campinas (SP), Brasil. Professor do curso de Medicina pela Universidade Estadual de Campinas (UNICAMP) - Campinas (SP), Brasil. andre.morcillo@gmail.com

${ }^{4}$ Doutor em Pediatria / Saúde da Criança e do Adolescente pela Universidade Estadua de Campinas (UNICAMP) - Campinas (SP). Professor do curso de Medicina da Universidade Estadual de Campinas (UNICAMP) - Campinas (SP), Brasil. teixeira@fcm.unicamp.br

${ }^{5}$ Mestranda em Fisioterapia pela Universidade do Estado de Santa Catarina (UDESC) - Florianópolis (SC), Brasil. mairaassumpcao@yahoo.com.br

'Doutora em Saúde da Criança e do Adolescente pela Faculdade de Ciências Médicas pela Universidade Estadual de Campinas (UNICAMP) - Campinas (SP), Brasil. Professora dos cursos de graduação e pósgraduação em Fisioterapia da Universidade do Estado de Santa Catarina (UDESC) -

Florianópolis (SC), Brasil.

cacaiss@yahoo.com
RESUMO Objetivo: elaborar uma proposta de assistência fisioterapêutica na rede básica de saúde objetivando sistematizar esse serviço para a saúde da criança e do adolescente. Método: revisão bibliográfica/pesquisa nas bases de dados Scielo, Lilacs e Medline. Resultados: o fisioterapeuta não apenas restaura, desenvolve e conserva a capacidade física do paciente, como também previne doenças e promove orientações. Assim, propõe-se sua atuação com base em três estratégias: orientação, assistência e acompanhamento. Conclusão: o fisioterapeuta na atenção primária pode efetivar sua integração na equipe multiprofissional das UBS, no apoio matricial e programas de saúde da família.

PALAVRAS CHAVE: Criança; saúde pública; atenção básica; fisioterapia.

\begin{abstract}
Objective: To develop a proposal for physical therapy in primary health aiming to systematize this service to child health and adolescent. Method: literature / research in Scielo, Lilacs and Medline. Results: the therapist not only restores, develops and retains the physical ability of the patient, also prevents diseases and promotes guidelines. Thus, we propose a performance based on three strategies: guidance, assistance and support. Conclusion: the physiotherapist in primary care can accomplish their integration into multidisciplinary team of basic health units in the matrix support programs and family health.
\end{abstract}

KEYWORDS: Child; public health; primary health care; physical therapy. 


\section{Introdução}

O direito à saúde como dever do Estado atualmente está garantido à população brasileira por meio do Sistema Único de Saúde (BRASIL, 2007b). O SUS propóe o acesso universal, integral, igualitário e intersetorial às açóes e serviços de promoção, proteção e recuperação da saúde, sendo as ações preventivas uma de suas prioridades (BRASIL, 2007c). Considerando esse conceito, existe relação entre o regimento do SUS e o papel do fisioterapeuta, uma vez que o código de ética desse profissional estabelece como uma de suas funçóes a atuação com caráter de prevenção.

Apesar deste processo ainda estar em construção, observamos que o profissional fisioterapeuta vem adquirindo crescente participação nos serviços referentes à atenção primária. Isso porque suas funções e atribuiçóes são constituídas por conjunto de ações de saúde, incluindo nessa esfera a prevenção, assim como o diagnóstico cinesiofuncional, tratamento, reabilitação e manutenção da saúde (BORGES et al., 2010), conforme o previsto no Conselho Federal de Fisioterapia e Terapia Ocupacional (COFFITO, 2008).

O termo prevenir habilita o fisioterapeuta a atuar na atenção básica, onde a prevenção das doenças é o maior enfoque. É sua função proporcionar educação, prevenção e assistência coletiva na atenção básica em saúde $(\mathrm{AB})$, bem como integrar equipes multiprofissionais destinadas a planejar, programar, controlar e executar projetos e programas (COFFITO, 2008).

Ainda é grande o esforço para se definir a atuação desse profissional na assistência primária pelo fato de haver pouca experiência acumulada nesse nível assistencial. Isso talvez decorra de inadequaçóes nas grades curriculares, da formação dos cursos de graduação e das legislaçóes vigentes, que caracterizam a assistência fisioterapêutica com caráter predominantemente curativo e reabilitador. Além disso, os próprios atores sociais desconhecem a prática de integralidade, conforme Silva e Da Ros (2006) apontaram recentemente.

Nesse contexto, os autores elaboraram uma proposta sistematizada de atuação da fisioterapia sobre os problemas e necessidades de saúde da criança ao adolescente, visando elucidar as características, a extensão e as possibilidades práticas deste profissional no nível básico de atenção.

\section{Método}

Para elaboração dessa proposta, foi realizada uma revisão bibliográfica de artigos científicos nas bases de dados SciELO, Lilacs e Medline, utilizando os seguintes Descritores em Ciências da Saúde (DeCS) na língua portuguesa: 'criança', 'saúde pública', 'atenção primária à saúde/atenção básica', 'fisioterapia' e na língua inglesa: 'child', 'public health', 'primary health care' e 'physical therapy'.

\section{Resultados}

Com base na revisão realizada, entendemos que compete ao fisioterapeuta o planejamento, a programação, a coordenação, a execução e a supervisão da aplicação de métodos e técnicas que visem à promoção da saúde, seja no nível de atenção básica, secundária ou terciária, englobando o paciente em todos os seus aspectos: físicos, emocionais e culturais.

A partir da integração desses conceitos - das responsabilidades do fisioterapeuta e das necessidades do paciente pediátrico -, elaborou-se uma proposta de atuação na atenção básica, que envolve três estratégias de intervenção: 'orientação', 'assistência' e 'acompanhamento', desenvolvidas nas Unidades Básicas de Saúde (UBS), através da inserção do fisioterapeuta neste espaço físico ou por meio do matriciamento.

\section{Síntese dos dados}

Foi verificada na literatura a abordagem das açôes fisioterapêuticas individuais e coletivas, uma vez que existe certa dificuldade de se encontrar referências sobre a atuaçáo do fisioterapeuta na $\mathrm{AB}$ de saúde (FORMIGA; RIBEIRO, 2012).

As ações individuais constituem o atendimento individual, visitas familiares, orientaçóes aos cuidadores, 
considerando a dificuldade de deslocamento até a UBS, devido a limitaçōes físicas, financeiras e à dinâmica familiar (BRAGA; COUTO ROSA; NOGUEIRA, 2008). Nesse contexto, a prática da visita domiciliar visa o primeiro contato com a moradia do usuário, sem necessariamente vinculá-lo ao atendimento, com possibilidade de orientaçóes e identificação de problemas locais (PORTES et al., 2011). As açôes comunitárias estão geralmente direcionadas à educação em saúde e práticas corporais, com a realização de atividades em creches, grupos escolares, envolvendo mulheres, gestantes e idosos. Podem ser oferecidas tanto em espaços específicos destinados às reuniôes ou nas próprias UBS, e incluem o desenvolvimento de palestras educativas, rodas de conversa ou atividades afins. (FORMIGA; RIBEIRO, 2012)

Assim, algumas possibilidades de atuação do fisioterapeuta na $\mathrm{AB}$ e em ambiente comunitário são apresentadas a seguir, mais especificamente foram abordadas questóes referentes à saúde e cuidado da criança, como a orientação, assistência e acompanhamento.

Orientaçáo: corresponde a programas de orientação por meio de palestras, treinamento aos pais, folhetos explicativos e outros veículos de comunicação, sobre diferentes assuntos que envolvem os cuidados com a criança. Através da apropriação do conhecimento, a criança e a família ganham autonomia no manejo da doença e na manutenção da saúde.

Devido à sua relevância, os temas: profilaxia ambiental, métodos de prevenção de acidentes domésticos, conscientização sobre o aleitamento materno e a imunização, orientações quanto a medidas antirreflexo, limpeza nasal, uso e higiene de inaladores devem ser abordados. Assuntos apontados pela comunidade como necessários, por meio de questionários e entrevistas, são incluídos nessa dinâmica. Em situações especiais, informaçóes são oferecidas quanto aos cuidados com a oxigenoterapia e o suporte ventilatório domiciliar.

Para o manejo de pacientes crônicos, são realizados programas de treinamento aos cuidadores envolvendo técnicas de fisioterapia respiratória e motora, na tentativa de garantir um cuidado domiciliar adequado. Orientaçóes para evitar agudizaçóes ou crises devem ser enfatizadas e uma atenção especial deve ser oferecida aos pacientes asmáticos, doença hoje responsável por elevado número de consultas na rede básica. Nas afecçóes respiratórias, o treinamento é dirigido para as técnicas de remoção de secreções brônquicas e exercícios ventilatórios.

$\mathrm{Na}$ área motora, este treinamento objetiva orientar os familiares para a prevençáo de encurtamentos e deformidades musculoesqueléticas, uso adequado de órteses, cuidados com escaras de decúbito e também na aplicação de estímulos para o desenvolvimento sensório-motor da criança.

Todo o programa de orientação leva em consideração o nível de entendimento dos cuidadores, a idade da criança, o quadro clínico em questáo, bem como os recursos disponíveis para a sua resolução.

Assistência: envolve o tratamento realizado diretamente pelo fisioterapeuta ao paciente pediátrico, realizado nas UBS ou no domicílio. É indicada para os casos de afecçóes respiratórias e motoras.

\section{Fisioterapia respiratória:}

$\mathrm{Na}$ área respiratória, a intervenção envolve a aplicação de técnicas convencionais (drenagem postural, vibração manual ou mecânica, percussão e padrôes ventilatórios) a fim de remover secreção brônquica, otimizar a ventilação pulmonar e melhorar o padrão respiratório da criança. Outras técnicas, denominadas modernas (ciclo ativo da respiração, técnica de expiração forçada e drenagem autógena), também podem ser utilizadas (LANNEFORS; BUTTON; MCILWAINE, 2004). Dado o perfil especial deste grupo etário, que necessita de motivação e incentivo, recursos lúdicos como bolhas de sabão, língua de sogra e apitos são bons coadjuvantes na terapia respiratória. Além do uso de algumas técnicas e instrumentais, como o inspirômetro de incentivo, o flutter $^{\circledR}$ e a tapotagem podem ser ensinados. Por serem recursos facilmente reproduzíveis pelo paciente ou cuidador bem treinado e orientado, promovem certa independência para manutenção do quadro respiratório (OBERWALDER, 2000).

\section{Fisioterapia motora:}

$\mathrm{Na}$ assistência das afecçóes motoras, o fisioterapeuta lança mão de exercícios, mobilizações, manipulaçóes, 
alongamentos e outros recursos que visam restabelecer a função musculoesquelética.

Nas alteraçóes posturais, o diagnóstico precoce aumenta as possibilidades de uma intervenção eficiente, principalmente na criança, onde o sistema musculoesquelético é mais complacente. Várias outras doenças requerem os cuidados do fisioterapeuta como: artrite reumatoide juvenil, doenças metabólicas, paralisia cerebral, miopatias, dentre outras.

Assim como nas enfermidades pulmonares, em muitos casos de alteraçóes motoras (ex: torcicolo muscular, pé torto congênito) o atendimento deve ser regular e conciliado com as orientaçóes aos cuidadores para realização de atividades em casa, o que efetiva o tratamento.

As crianças prematuras com patologias limitantes ou restritas ao leito estão sujeitas a complicaçôes como: atraso no desenvolvimento neuropsicomotor, escaras de decúbito, alteraçóes no sistema musculoesquelético (hipotrofia, atrofia muscular, contraturas, osteoporose precoce, osteopenia e deformidades) (FELÍCIO; BARROS; VOLPON, 2005). O acompanhamento regular na primeira infância e avaliaçóes fisioterapêuticas programadas permitem detectar precocemente atrasos ou desvios, orientar os pais sobre as características da criança pré-termo, ensinar princípios básicos de estimulação sensório-motora, anotar dados sobre o crescimento e desenvolvimento das crianças acompanhadas na caderneta infantil. Quanto mais precoce as intervençôes, maiores as chances de normalização sem defasagem no desenvolvimento (MAGALHÁES et al., 2003).

Outra intervenção, diz respeito aos quadros álgicos, que são responsáveis por um elevado número de consultas nas UBS. A redução da dor melhora o desempenho do paciente durante a terapia, além de restituir sua qualidade de vida. A acupuntura e a estimulação elétrica nervosa transcutânea são recursos com bons resultados analgésicos (RABAINA, 1989). Outros procedimentos, como massoterapia, relaxamento, hidroterapia e cinesioterapia, também propiciam o alívio sintomático da dor, possibilitando a redução do uso de fármacos (OKADA; TEIXEIRA; MIYAGI, 2001).
Acompanhamento: trata-se do seguimento da criança e do adolescente. O fisioterapeuta estabelece formas de monitorar a criança, seja através da programação de retornos semanais às UBS ou por meio de visitas domiciliares. Esse acompanhamento pode ser feito de forma direta ou indireta.

Quando direta, o profissional programa retornos periódicos nos quais ele realiza a avaliação do desenvolvimento e do crescimento da criança, analisa aspectos sensoriais e motores, reforça orientaçóes realizadas e ainda retoma os cuidados quanto às doenças respiratórias e quanto ao manejo de pacientes crônicos. Assim, avalia a evolução da criança e do adolescente, identifica precocemente alteraçóes motoras e posturais, agudizaçôes do quadro respiratório e ainda monitora as condiçóes domiciliares. Esse contato direto viabiliza o encaminhamento da criança para avaliação multiprofissional e a intensificação da assistência fisioterapêutica, quando necessária.

Já no acompanhamento indireto, o fisioterapeuta verifica regularmente os registros da caderneta de saúde da criança, com o objetivo de promover a vigilância à saúde infantil. Elaborada pelo Ministério da Saúde, é uma importante ferramenta que os profissionais da saúde dispóem para acompanhar a adequação do crescimento e do desenvolvimento (BRASIL, 2007a).

A corrente proposta apresentada, de atuação do fisioterapeuta na rede básica de saúde por meio das três estratégias de intervenção - orientação, assistência e acompanhamento -, fornece uma perspectiva ampla e integral do paciente pediátrico, viabilizando uma terapêutica multiprofissional mais efetiva. Quando implantada por um programa que esteja integrado às equipes de referência e parte do apoio matricial, pode garantir o atendimento fisioterapêutico ao usuário do serviço para o qual ele é referência, além dos seus próprios usuários.

\section{Discussão}

A profissão da fisioterapia foi regulamentada no Brasil em 1969, cuja finalidade consistia em restaurar, desenvolver e conservar a capacidade física do indivíduo. Dez anos após, seu leque de atuação ampliou-se para 
os níveis de atenção básico, secundário e terciário (LUCAS, 2005). Contudo, pela sua própria concepção e formação ao modelo assistencial curativo, a fisioterapia muitas vezes é vista somente como reabilitadora de sequelas e complicações quando a doença já está instalada. Esse conhecimento limitado restringe a atuação do profissional e destaca o pensamento popular, no qual o fisioterapeuta somente está inserido nos espaços tradicionalmente conhecidos (hospitais e clínicas de reabilitação). Nessa linha, predomina a visão que a fisioterapia destina-se apenas à recuperação de distúrbios ortopédico-traumatológicos e neurológicos (BISPO JR., 2010).

Esse pensamento foi historicamente construído: na Antiguidade a principal preocupação na área da saúde era tratar as doenças; no Renascimento, a divisão entre os profissionais que deveriam reabilitar pessoas com alguma morbidade e aqueles que cuidariam da saúde de pessoas hígidas parece ter contribuído para que o objeto de trabalho da fisioterapia permanecesse direcionado ao atendimento de pessoas já enfermas; seguindo com a industrialização e proliferação de novas doenças, aumentou o interesse pelo tratamento de enfermidades e suas sequelas; no Brasil, por volta de 1879, teve início o uso de recursos físicos com o intuito de curar e reabilitar doentes. Posteriormente, na década de 50, a alta incidência de poliomielite e de acidentes de trabalho fortaleceu ainda mais a concepção da fisioterapia como reabilitadora (SILVA et al., 2007).

Atualmente, o processo de formação do fisioterapeuta está direcionado a desenvolver competências e habilidades gerais para atenção à saúde, como açóes de prevenção, promoção e proteção da saúde, além da reabilitação individual e coletiva. A graduação tem um perfil mais humanista, crítico, reflexivo e capacitado a atuar em todos os níveis de atenção (CONSELHO FEDERAL DE FISIOTERAPIA E TERAPIA OCUPACIONAL, 2009). No entanto, o discente ainda tem um conhecimento limitado sobre as possibilidades de sua atuação na saúde pública, visto a escassez do número de profissionais nesta área (NAVES; BRICK, 2011).

Nos serviços de atenção primária destinados ao primeiro contato do paciente com o sistema de saúde, visa-se cobrir as afecçóes mais frequentes e resolver a maioria dos problemas de saúde de uma populaçáo (GIOVANELLA, 2006). Sendo que a contemplação com ações vinculadas aos setores da Atenção Básica $(\mathrm{AB})$ é recente, e realizada por meio do trabalho em conjunto com a equipe multiprofissional nas UBS e em alguns Programas de Saúde em Família (PSF) (BRASIL et al., 2005).

No modelo tradicional, as UBS configuram uma organização territorial, um espaço físico ou até político operativo do SUS para a prevenção e promoção de saúde (BARBOSA et al., 2010). No Brasil, as UBS trabalham com dois modelos de atenção: o tradicional, no qual a organização dos serviços de saúde acontece por meio de demanda espontânea ou programada, ou através da Estratégia de Saúde da Família (ESF) (TRINDADE, 2012). Nas UBS, a atuação da fisioterapia pode ser desenvolvida através desses dois modelos com açôes de educação em saúde, atividades domiciliares, atividades em grupos, atendimentos individuais, ações intersetoriais, acolhimento e investigação epidemiológica (PORTES et al., 2011).

Dentro das ESF, e com a ampliação da cobertura assistencial (FORMIGA; RIBEIRO, 2012), o Ministério da Saúde criou o Núcleo de Apoio à Saúde da Família (NASF). O profissional da fisioterapia compóe essa equipe, que tem como proposta a integralidade do SUS, a ampliação das ações de atenção básica e a interação com outros profissionais (NASCIMENTO; OLIVEIRA, 2010). No NASF, o fisioterapeuta está apto a planejar, implementar, controlar e executar políticas, programas, cursos, pesquisas ou eventos em saúde pública, contribuindo com planejamento, investigação e estudos epidemiológicos. Também pode participar de câmaras técnicas de padronização de procedimentos em saúde coletiva; avaliar qualidade, eficácia e riscos à saúde decorrentes de equipamentos de uso fisioterapêutico. Além disso, pode promover assistência organizada em acolhimento, atendimento individual, domiciliar, grupos operativos e atividades educativas em equipe (BARBOSA et al., 2010).

Dentre os grupos assistidos, que contam com políticas de atenção primária, como a saúde na área da mulher, do trabalhador, do idoso, o enfoque do corrente artigo é a atenção dada à criança e adolescente no que se refere às práticas da fisioterapia. 
Como uma grande parte das doenças pediátricas requer a atuação da fisioterapia e se beneficia com o tratamento, a ação sistematizada deste profissional pode contribuir para redução na demanda de consultas as UBS, bem como na morbidade desse grupo etário. A casuística do atendimento pediátrico presente na rede também justifica a presença deste profissional, pois há um número elevado de consultas por situaçôes de insuficiência respiratória aguda, exacerbaçóes de pneumopatias crônicas, debilidades do quadro motor de diferentes etiologias, queixas álgicas e alteraçóes posturais de escolares e adolescentes. Para essas afecçóes, a fisioterapia conta com recursos e técnicas manuais que podem prevenir agravos e tratar quadros instalados, por meio do auxílio na remoção de secreção brônquica e pela recuperação funcional através de exercícios e mobilizaçóes.

A população infantil é um dos grupos etários mais vulneráveis e é assistido por meio de políticas através do programa de saúde da criança. Este programa tem como responsabilidades a garantia dos aspectos nutricionais, reforço constante quanto ao aleitamento materno, acompanhamento regular do crescimento e do desenvolvimento da criança, imunização por meio de campanhas de vacinação, e ainda assistência às doenças prevalentes, como diarreia e infecções respiratórias agudas.

Entre as afecçóes mais comuns na criança, estão as enfermidades respiratórias. As infecções respiratórias agudas (IRAs) têm relevância universal. Elas constituem importante causa de adoecimento em crianças até os cinco anos de idade e têm elevada morbidade e mortalidade na infância, particularmente nos países em desenvolvimento (NIOBEY et al., 1992; RODRIGUES; SILVA; BUSH, 2002). No Brasil, parcela significativa da morbidade e da mortalidade infantis relaciona-se a causas evitáveis, dependentes das melhorias dos serviços de saúde e investimentos em educação e saneamento básico (RABELAIS, 2007).

A fisioterapia respiratória é utilizada com frequência no tratamento das doenças respiratórias pediátricas e muitos estudos avaliam os benefícios desta intervenção. Um estudo realizado em 2002 mostrou que a fisioterapia contribuiu para a redução do número de ocorrências de pneumonias em crianças (BRUNETTO, 2002).

Existe evidência de que a aplicação de técnicas de fisioterapia respiratória para o tratamento de afecçóes respiratórias na infância contribui para uma melhor recuperação dos pacientes (JANOSKI, 1990). Portanto, a inclusão deste profissional na rede facilita o acesso da população infantil a essa terapêutica, cujos benefícios estáo retratados na literatura (VAN DER SCHANS et al., 1999), principalmente na asma, bronquiolite e crises de 'chiado' do lactente.

Fatores individuais e do ambiente de vida da criança propiciam o aparecimento de doenças e sua evoluçáo, em especial nos dois primeiros anos de vida, em função de sua característica anatômica e imunológica. A exposição a fatores irritativos e sensibilizantes, ambientes frios e úmidos, conglomerados, são aspectos domiciliares que explicam os episódios de doenças respiratórias em crianças que residem em áreas urbanas, com recidivas, em média, de seis a oito vezes por ano (SÃO PAULO, 2003).

Além das afecçóes respiratórias, Portes et al. (2011) destacam que há a necessidade de mais trabalhos envolvendo crianças com os outros acometimentos comuns a esse ciclo de vida, considerando que existe precariedade quanto ao levantamento das reais necessidades que esse grupo etário depende.

Nessa linha, os quadros motores apresentam altos índices de procura por assistência em saúde, tendo a fisioterapia benefícios reconhecidos. Em situações como o atraso do desenvolvimento motor infantil, seja devido à prematuridade ou decorrente de encefalopatias, é uma terapêutica reconhecida como eficiente coadjuvante da clínica médica.

As variaçóes posturais são comumente encontradas no período do crescimento e do desenvolvimento e decorrem dos vários ajustes, das adaptaçôes, de mudanças corporais e psicossociais que marcam esta fase (PENHA et al., 2005). Observa-se um aumento relevante na incidência de problemas posturais em crianças, sendo as causas mais comuns: má postura durante as aulas, uso incorreto da mochila escolar, utilização de calçados inadequados, sedentarismo e obesidade. Através de uma avaliação fisioterapêutica minuciosa da postura, 
consegue-se identificar alteraçóes que podem trazer consequências prejudiciais à função de sustentação e de mobilidade (BANKOFF; BRIGHETTI, 1986), bem como iniciar precocemente a terapêutica adequada e reverter o quadro.

Também o ganho ponderal das crianças resulta de apoio e orientação que as mães recebem durante o processo de amamentação (ONIS; VICTORA, 2004). O fisioterapeuta, através da proposta do acompanhamento indireto, pode reforçar as orientaçóes, além de verificar a caderneta de saúde regularmente e, juntamente com a equipe multiprofissional, verificar a adequação do desenvolvimento pôndero-estatural.

Entretanto, Sousa, Erdmann e Mochel (2011) destacam a ocorrência das condiçóes limitadoras para integralidade do cuidado à criança na $\mathrm{AB}$ da saúde. Relatam que, apesar de açôes para esse grupo serem enfatizadas, ainda encontram-se em processo de formação e implementação. Deve haver a interação entre o profissional da equipe, as famílias e a própria comunidade, o que na prática não é tão simples.

Contudo, em sua revisão, Loures e Silva (2010) verificam a interface entre as atuaçôes do agente comunitário e o fisioterapeuta, e relatam haver uma interação entre suas atividades. Esse fato fortalece o trabalho desses profissionais na atenção básica, no que concerne à importância da realização do trabalho em equipe.

Em um estudo realizado no município de Sobral (Ceará), onde o fisioterapeuta participa diretamente no programa de saúde da família, foi constatado que $67 \%$ das atividades fisioterapêuticas se relacionam com a promoção de saúde e geram um alto índice de satisfação popular (BRASIL et al., 2005). O modelo estruturante do PSF deste município incorpora várias categorias profissionais de saúde ao programa, permitindo o desenvolvimento de açóes de muita importância e impacto na qualidade de vida da população. Os impactos podem ser sentidos na saúde da criança, onde há estudos que mostram redução significativa da desnutrição no primeiro ano de vida, mortalidade neonatal, mortalidade infantil geral e por diarreia (SIQUEIRA; FACCHINI; HALLAL, 2005).

Também em Ipatinga (MG), há evidências suficientes que demonstram que a fisioterapia, quando integrada na equipe do PSF, melhora significativamente o quadro geral de saúde dos pacientes (CONSELHO FEDERAL DE FISIOTERAPIA E TERAPIA OCUPACIONAL, 2005). Estes resultados motivam a sistematização da ação do fisioterapeuta no PSF, cujas açóes podem levar a um grande impacto na saúde da criança.

Um fato importante a destacar é que a maioria da população que utiliza os serviços de saúde o faz através do SUS. Em estudo realizado no estado do Rio Grande do Sul verificou-se que, entre os usuários de fisioterapia, 66\% utilizam o SUS, 25\% planos de saúde ou convênios e 9\% consultas particulares (SIQUEIRA; FACCHINI; HALLAL, 2005). Sistematizar a atuação da fisioterapia no nível de atenção básica, com vistas à promoção da saúde e prevenção de doenças, corrobora com a proposta a que este nível de atenção se dispóe (GIOVANELLA, 2006).

No entanto, diante da complexidade das questóes que envolvem os cuidados com a criança e o adolescente, fica claro que atuar na $A B$ não é tarefa simples. $A$ compreensão e a inserçáo do profissional na comunidade devem ser adquiridas pela educação permanente, bem direcionada e elaborada (PAULA et al., 2009; RIBEIRO; SILVA; PUCCINI, 2010).

Isso porque, conforme afirma Fréz e Nobre (2011), o planejamento e o direcionamento das políticas públicas relacionadas à saúde são cada vez mais acertadas quanto mais fundamentadas estão no respeito às perspectivas e necessidades daqueles que a utilizam. São os usuários os mais passíveis de percepção e análises. No caso das crianças, esta tarefa se destina aos pais, que devem ser educados, orientados e ouvidos com relação às necessidades em saúde e à satisfação com os serviços de atendimento aos seus filhos.

Importante destacar ainda que a organização atual do SUS, em equipes de referência e apoiadores matriciais, que visam a ampliação das possibilidades de realizar uma clínica abrangente e uma integração dialógica entre as diferentes especialidades (CAMPOS; DOMITTI, 2007), tem como finalidade garantir às equipes das UBS um maior apoio no processo de assistência (ARONA, 2009). Esse cenário ainda está em fase de construção e envolve alguns obstáculos como a própria estrutura, o 
excesso de demanda e a carência de recursos, no âmbito político, de comunicação, cultural, ético e epistemológico (CAMPOS; DOMITTI, 2007), e que configuram barreiras a todos os profissionais, incluindo os fisioterapeutas. No caso desses profissionais, são escassos os relatos quanto a tais experiências e discussôes conceituais sobre a importância de suas açóes no matriciamento. Essa lacuna necessita ser sanada, para que a prática da fisioterapia na $\mathrm{AB}$ seja constituída de fato, bem como se defina suas relaçóes com outros promotores da saúde e seu real foco de atuação.

Apesar dos problemas citados, essa nova organização cria as condiçóes para a definitiva incorporação desse tipo de atendimento, por facilitar a interlocução multiprofissional e a gestão do procedimento e tais atividades têm envolvido a orientação aos familiares, auxílio no manuseio da criança doente e prevenção de enfermidades comuns desta faixa etária. Porém, por não haver uma descrição sistematizada da atuação deste profissional na $A B$ com enfoque na saúde da criança e do adolescente, houve o interesse em apresentar essa proposta.

\section{Conclusão}

A proposta de atuação do fisioterapeuta na rede básica de saúde aqui apresentada sistematiza a participação deste profissional na equipe multiprofissional, de forma transdisciplinar e horizontal, além de caracterizar sua função, que não se restringe apenas à reabilitação, mas também à promoção da saúde, conforme rege o SUS. Por se tratar de uma proposta organizada de inserção deste profissional no nível primário de atenção, pode não só beneficiar o sistema, reduzindo a sobrecarga nos níveis secundário e terciário de assistência, como também viabilizar o acesso da criança e do adolescente à fisioterapia.

\section{Referências}

ARONA, E. C. Implantação do matriciamento nos serviços de saúde de Capivari. Saúde e Sociedade, São Paulo, v. 18, n. 1, p. 27-36, 2009.

BANKOFF, A. D. P.; BRIGHETTI, V. Levantamento de incidência de cifose postural e ombros caídos em alunos de $1^{\text {a à }} 4^{a}$ série escolar. Revista Brasileira de Ciências do Esporte, Porto Alegre, v. 7, n. 3, p. 93 97, 1986

BARBOSA, E. G.; FERREIRA, D. L. S.; FURBINO, S. A. R. Experiência da fisioterapia no Núcleo de Apoio à Saúde da Família em Governador Valadares, MG. Fisioterapia em movimento, Curitiba, v. 23, n. 2, p. 323330,2010

BISPO JR, J. P. Fisioterapia e saúde coletiva: desafios e novas responsabilidades profissionais. Ciência e Saúde Coletiva, Rio de Janeiro, v. 15, n.1, p. 1627-1636, 2010

BORGES, A. M. P. et al. A contribuição do fisioterapeuta para - Programa de Saúde da Família - uma revisão da literatura. UNICiências, Cuiabá, v. 14, n. 1, p. 69-82, 2010.

BRAGA, A. F. ; COUTO ROSA, K. O.; NOGUEIRA, R. L. Atuação do fisioterapeuta nas equipes de saúde da família. Investigação, Franca, v. 8, n. 1-3, p. 19-24, 2008.
BRASIL, A. C. O. et al. O papel do fisioterapeuta do programa saúde da família do município de Sobral - Ceará. Revista Brasileira de Promoção de Saúde, Fortaleza, v. 18, n.1, p. 3-6, 2005.

BRASIL. Ministério da Saúde. Caderneta de saúde da criança. Disponível em: <http://bvsms.saude.gov.br/bvs/publicacoes/ menina_final.pdf>. Acesso em: 26 jun 2007a.

Sistema Único de Saúde. SUS: Aspectos gerais. Disponível em: <http://www.sespa.pa.gov.br/SUS/sus/sus_aspgerais.htm>. Acesso em: 28 maio 2007b.

Sistema Único de Saúde. SUS: O que é o SUS. Disponível em: <http://www.sespa. pa.gov.br/Sus/sus/ sus_oquee.htm>. Acesso em: 28 jul. 2007c

BRUNETTO, A. F.; PAULIN, E. Importância da fisioterapia pulmonar no tratamento de pneumonias em crianças. Revista Fisioterapia em Movimento, Curitiba, v. 15, n. 1, p. 39-45, 2002.

CAMPOS, G. W. S.; DOMITTI, A. C. Apoio matricial e equipe de referência: uma metodologia para a gestão do trabalho interdisciplinar na saúde. Cadernos de Saúde Pública, Rio de Janeiro, v. 23, n. 2, p. 399-407, 2007. 
CONSELHO FEDERAL DE FISIOTERAPIA E TERAPIA OCUPACIONAL (Brasil). Saúde da Família: uma nova opção para o trabalho do fisioterapeuta e terapeuta ocupacional. Revista trimestral do COFFITO, Brasília, v. 7, n. 24, p. 6-8, 2005.

Disponível em: <http://www.coffito.org.br/\#[page] showDynamic.php?page=6\&section=6\&pagina=fisio_defin. $>$. Acesso em: 15 maio 2008.

Diretrizes Curriculares. Disponível em: <http://www. crefito10.org.br/open.php?id_ses=4\&pk=22>. Acesso em 10 jun. 2010.

FELÍCIO, L. R.; BARROS, A. R. S. B.; VOLPON, J.B. Abordagem fisioterapêutica em crianças com doença de Legg-CalvéPerthes submetidas à instalação do artrodistrator: estudo de caso. Fisioterapia e Pesquisa, São Paulo, v. 11, n. 1, p. 37-42, 2005.

FORMIGA, N. F. B. ; RIBEIRO, K. S. Q. S. Inserção do fisioterapeuta na $A B$ : uma analogia entre experiências acadêmicas e a proposta dos Núcleos de Apoio à Saúde da Família (NASF). Revista Brasileira de Ciências da Saúde, São Caetano do Sul, v. 16, n. 2, p. 113-122, 2012.

FRÉZ, A. R.; NOBRE, M. I. R. Satisfação dos usuários dos serviços ambulatoriais de fisioterapia da rede pública. Revista Fisioterapia em Movimento, Curitiba, v. 24, n. 3, p. 419-428, 2011.

GIOVANELLA, L. Primary care in European Union countries: configurations and organizational reforms in the 1990s. Cadernos de Saúde Pública, Rio de Janeiro, v. 22, n. 5, p. 951963, 2006.

JANOSKI, J. C. B. Abordagem da fisioterapia respiratória em paciente pediátrico. Revista Fisioterapia em Movimento, Curitiba, v. 3, n. 1, p. 89-101, 1990.

LANNEFORS, L.; BUTTON, B. M.; MCILWAINE, M. Physiotherapy in infants and young children with cystic fibrosis: current practice and future developments. Journal of Royal Society Medicine, London, v. 97, n. 44, p. 8-25, 2004.

LOURES, L. F.; SILVA, M. C. S. A interface entre o trabalho do agente comunitário de saúde e do fisioterapeuta na $A B$ à saúde. Ciência \& Saúde Coletiva, Rio de Janeiro, v. 5, n. 4, p. 2155-2164, 2010.

LUCAS, R.W.C. Fisioterapia: denominação inadequada para uma atuação profissional moderna. Conhecimento Interativo, São José dos Pinhais, v. 1, n. 1, p. 89-97, 2005.

MAGALHÃES, L. C. et al. Estudo comparativo sobre o desempenho perceptual e motor na idade escolar em crianças nascidas pré-termo e a termo. Arquivos de NeuroPsiquiatria, São Paulo, v. 61, n. 2A, p. 250-255, 2003.
NASCIMENTO, D. D. G. ; OLIVEIRA, M. A. C. Reflexões sobre as competências profissionais para o processo de trabalho nos Núcleos de Apoio à Saúde da Família. O Mundo da Saúde, São Paulo, v. 34, v. 1, p. 92-96, 2010.

NAVES, C. R.; BRICK, V. S. Análise quantitativa e qualitativa do nível de conhecimento dos alunos do curso de fisioterapia sobre a atuação do fisioterapeuta em saúde pública. Ciência \& Saúde Coletiva, Rio de Janeiro, v. 16, n. 1, p. 1525-1534, 2011.

NIOBEY, F. M. L. et al. Fatores de risco para morte por pneumonia em menores de um ano em uma região metropolitana do sudeste do Brasil: um estudo tipo caso-controle. Revista Saúde Pública, São Paulo, v. 23, n. 4, p. 229-238, 1992.

OKADA, M.; TEIXEIRA, M. J.; MIYAGI, K. T. Tratamento da dor em pediatria. Revista de Medicina, São Paulo, v. 80, n. 1, p. 157-169, 2001.

ONIS, M.; VICTORA, C. G. Growth charts for breastfed babies. The Journal of Pediatrics, Cincinnati, v. 80, n. 2, p. 85-87, 2004.

PAULA, R. et al. Fisioterapia na comunidade: Saúde da Família, novos desafios e desenvolvimento das ações no trabalho multiprofissional. Revista Multidisciplinar das Faculdades Integradas Pitágoras, Montes Claros, v. 1, n. 7, p. 64-70, 2009.

PENHA, P. J. et al. Postural assessment of girls between 7 and 10 years of age. Clinics, São Paulo, v. 60, n. 1, p. 9-16, 2005.

PORTES, L. H. et al. Atuação do fisioterapeuta na Atenção Básica à Saúde: uma revisão da literatura brasileira. Revista de APS, Juiz de Fora, v. 14, v. 1, p. 111-119, 2011.

RABELAIS, D. C. M. Reflexos das políticas de saúde sobre as tendências da mortalidade infantil no Brasil: revisão da literatura sobre a última década. Cadernos de Saúde Pública, Rio de Janeiro, v. 23, n. 7, p. 1511-1528, 2007.

RIBEIRO, A. M. R.; SILVA, R. R. F.; PUCCINI, R. F. Conhecimentos e práticas de profissionais sobre desenvolvimento da criança na $A B$ à Saúde. Revista Paulista de Pediatria, São Paulo, v. 28, n. 2, p. 208-301, 2010.

RODRIGUES, J. C.; SILVA, F. L. V. F.; BUSH, A. Diagnóstico etiológico das pneumonias: uma visão crítica. The Journal of Pediatrics, Cincinnati, v. 78, n. 2, p. 229-140, 2002.

SÃO PAULO. Secretaria Municipal de Saúde. Caderno temático da criança. Disponível em: http://ww2.prefeitura. sp.gov.br//arquivos/secretarias/saude/publicacoes/0001/ CadernoCrianca.pdf.>. Acesso em: 3 jun 2009.

SILVA, D. J.; DA ROS, M. A. Inserção de profissionais de fisioterapia na equipe de saúde da família e SUS: desafios na formação. Ciência \& Saúde Coletiva, Rio de Janeiro, v. 12. n. 6, p. 673-681, 2007. 
SILVA, E. et al. A importância da pesquisa científica para o profissional fisioterapeuta. Disponível em: <http://www. estacio.br/graduacao/fisioterapia/artigos/importância_ pesquisa. pdf />. Acesso em: 26 jun. 2007.

SIQUEIRA, F. V.; FACCHINI, L. A.; HALLAL, P. C. Epidemiology of physiotherapy utilization among adults and elderly. Revista de Saúde Pública, São Paulo, v. 39, n. 4, p. 662-668, 2005.

SOUSA, F. G. M.; ERDMANN, A. L.; MOCHEL, E. G. Condições limitadoras para a integralidade do cuidado à criança na $A B$ de saúde. Texto e Contexto Enfermagem, Florianopólis, v. 20, n. spe, p. 263-271, 2011.

TRINDADE, K. M. Fisioterapia em uma unidade básica de saúde: estudo da demanda espontânea. 2012, 49 f. Dissertação (Mestrado em Ciências) - Faculdade de Medicina, Universidade de São Paulo, São Paulo, 2012.

VAN DER SCHANS, C. P. A. et al. Physiotherapy and bronchial mucus transport. European Respiratory Journal, Le Kremlin-Bicêtre, v.13, n. 6, p. 1477-1486, 1999.

Recebido para publicação em Agosto/2012

Versão final em Março/2013

Conflito de interesses: Não houve.

Suporte financeiro: Inexistente. 